\title{
A primer for success in science
}

\section{BOOK TITLE:}

Success strategies from women in STEM: A portable mentor (2nd ed)

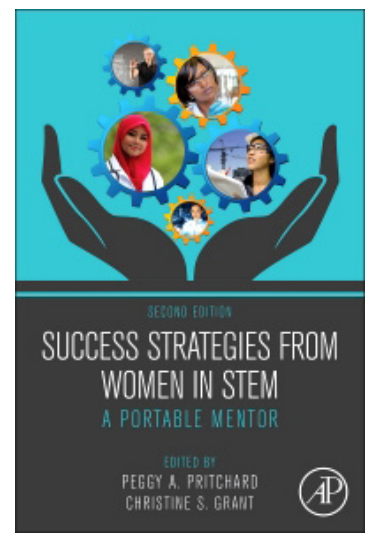

\section{EDITORS:}

Peggy A. Pritchard,

Christine S. Grant

ISBN:

9780123977755 (ebook)

\section{PUBLISHER:}

Academic Press, San Diego; USD44.95

\section{PUBLISHED: \\ 2015}

\section{REVIEWER:}

Brenda Wingfield ${ }^{1}$

\section{EMAIL:}

Brenda.Wingfield@up.ac.za

\section{AFFILIATION:}

${ }^{1}$ Faculty of Natural and Agricultural Sciences, University of Pretoria, Pretoria, South Africa

\section{POSTAL ADDRESS:}

Faculty of Natural and Agricultural Sciences, University of Pretoria, Private Bag X20, Hatfield 0028, South Africa

\section{HOW TO CITE:}

Wingfield B. A primer for success in science. S Afr J Sci. 2016;112(7/8), Art. \#a0165, 1 page. http://dx.doi. org/10.17159/sajs.2016/a0165
This book is extremely useful and is strongly recommended. However, the language is dense to read; it is not the kind of book that can be read from cover to cover in one or two sittings - or even three. I suspect that the authors never meant it to be read this way, as each chapter is really a stand-alone entity.

My overriding comment is that this book is not for only women. The strategies, in most cases, are as useful for men as they are for women. Indeed, I would recommend this book as essential reading matter for all young academics in the field of science, technology, engineering and mathematics (STEM). That is not to say more mature academic readers could not learn from the book, but many of the strategies discussed are perhaps most useful for those who are starting out or are still doing their graduate studies. I certainly would have liked to read many of the chapters while much younger. Of course, the question is whether I would have really understood what I was reading and whether I would have acted on the information.

The book starts with a very interesting chapter on career management, followed by a chapter on networking and then a chapter on mentoring. These three chapters overlap, but the messages are very clear. With the hindsight of a long career in STEM, I support much of what is covered and suggested. Chapter 4, on mental toughness, is in a different vein but equally important. It is one of the chapters that focus on women and it highlights some of the common mistakes women make. Chapter 5, titled 'Time stress', highlights some important issues - including one of my personal favourites, the issue of juggling 'important' versus 'urgent' tasks. The chapter includes a very useful table which explains the differences. I would be tempted to say that everyone should have this table displayed on a wall where they can see it daily.

Chapter 6 rather nicely talks about personal style. Often young women - and men - do not fully believe the idiom 'clothes make the man'. First impressions do count, and you need to think about what these impressions say about you. Clothes are not everything; the chapter also discusses action and voice. For example, women's voices and speech patterns are often softer than men's, and may be less likely to command respect and attention. Chapter 7 follows up on this topic rather well. It provides sound advice for how scientists should communicate, and includes a list of dos and don'ts - which I thought was particularly appropriate.

Chapter 8 is an obvious addition to the book, as it talks about social media. This is something I have less experience with, and I will go back to the chapter to learn more. This chapter is followed by a chapter on negotiation, which again should be read by both men and women. The most useful 'take home' message is that negotiations are a process - something our younger generations are less likely to understand. Our young scientists are part of Generation $Y$ and expect things to happen instantaneously, but negotiations do not happen this way.

The chapter on leadership is very well written. It too contains some useful tables, but is extremely dense. I think the most important message of the chapter is that one needs to define one's own style. However, this message gets a bit lost in the detail, despite the many tables being important and interesting. I found the chapter on 'climbing the ladder' less compelling, and the penultimate chapter on balancing one's professional and personal life was unsatisfying. Some of the statistics given in this chapter are quite alarming, and suggest that the most common reason for women not to continue in full-fledged academic careers relates to child bearing and rearing. I am not convinced there is anything balanced about reaching the top rungs of an academic career. One of the problems is that we need to be clearer, early on in mentoring young academics - particularly young women - about what it takes to succeed in academia. This is not to frighten people off but to enable them to deal with the reality and plan accordingly. Such mentorship should include giving them the tools to cope. Somehow this is not done, and women end up having to make difficult decisions in a vacuum.

The book ends with a chapter on transitions. This chapter is another that contains messages for men as well as women. It is also applicable not only to STEM but to all careers. The examples used are for STEM, and tend to focus on the fact that people in STEM are likely to move around geographically, and this is likely to make transitions from one stage to the next - such as school to university - quite complex.

This book is a very useful summary of many different aspects that STEM professionals are likely to encounter as they climb the professional ladder. The book includes many different stories and in this way gives examples of situations STEM professionals are likely to encounter. All examples are drawn from women's lives and this makes the book perhaps more accessible to women. However, all the examples come from North America, making the book perhaps a bit biased. Despite this, I found that many of the examples resonated strongly. I suggest that all young academics and STEM professionals should have this book as a reference to use as they embark on their careers. I will be recommending particular chapters to some of the academics I mentor. 